\title{
Hydrogen effect on the mechanical behaviour and microstructural features of a Fe-Mn-C twinning induced plasticity steel
}

\author{
Xiaofei Guo ${ }^{1)}$, Stefan Zaefferer ${ }^{2)}$, Fady Archie ${ }^{3)}$, and Wolfgang Bleck ${ }^{1)}$ \\ 1) Steel Institute, RWTH Aachen University, Intze-str. 1, Aachen 52072, Germany \\ 2) Max-Planck-Institut für Eisenforschung GmbH, Max-Planck-Straße 1, Düsseldorf 40237, Germany \\ 3) NLMK Europe, Eutelis-Platz 2, Ratingen 40878, Germany \\ (Received: 13 January 2021; revised: 19 March 2021; accepted: 22 March 2021)
}

\begin{abstract}
The influences of hydrogen on the mechanical properties and the fracture behaviour of $\mathrm{Fe}-22 \mathrm{Mn}-0.6 \mathrm{C}$ twinning induced plasticity steel have been investigated by slow strain rate tests and fractographic analysis. The steel showed high susceptibility to hydrogen embrittlement, which led to $62.9 \%$ and $74.2 \%$ reduction in engineering strain with 3.1 and 14.4 ppm diffusive hydrogen, respectively. The fracture surfaces revealed a transition from ductile to brittle dominated fracture modes with the rising hydrogen contents. The underlying deformation and fracture mechanisms were further exploited by examining the hydrogen effects on the dislocation substructure, stacking fault probability, and twinning behaviour in pre-strained slow strain rate test specimens and notched tensile specimens using coupled electron channelling contrast imaging and electron backscatter diffraction techniques. The results reveal that the addition of hydrogen promotes planar dislocation structures, earlier nucleation of stacking faults, and deformation twinning within those grains which have tensile axis orientations close to $<111>/ /$ rolling direction and $<112>/ /$ rolling direction. The developed twin lamellae result in strain localization and micro-voids at grain boundaries and eventually lead to grain boundary decohesion.
\end{abstract}

Keywords: twinning induced plasticity steel; hydrogen; mechanical behaviour; dislocation; twinning; electron channelling contrast imaging

\section{Introduction}

High manganese austenitic steels achieve an excellent combination of strength and ductility thanks to the twinning induced plasticity (TWIP) effect. The formation of deformation twins as a mechanism of dynamic strain hardening provides substantial obstacles for dislocation gliding, thus achieving high strain hardening capacity [1-2]. Despite excellent uniform elongation, TWIP steels usually show an abrupt fracture behaviour without undergoing obvious necking. This limited necking is particularly attributed to the sudden multiplication of voids introduced by twin-twin or twin-grain boundary interactions [3]. This material group is also reported vulnerable to hydrogen embrittlement (HE), which leads to catastrophic failure under static or cyclic forces [4-6].

HE mechanisms in structure steels have been intensively investigated from various perspectives [7-15]. Several mechanisms have been proposed according to microscopic observation $[7,9,13]$ or quantum mechanical based calculations on hydrogen-dislocation interactions [16-17]. The hydrogen-enhanced decohesion (HEDE) theory demonstrates that the dissolved hydrogen reduces the cohesive strength of the intermetallic bonds, which was supported by the frequently observed brittle fracture mode [11] and large attraction of hydrogen to grain boundaries and particle-matrix interfaces [18-19]. Beachem [7] observed that hydrogen facilitates dislocation movement in environmental transmission electron microscope (TEM) chamber and proposed it as the hydrogenenhanced localised plasticity (HELP) theory. Lynch [8] interpreted the theory as the enhanced dislocation emission from crack tip, where hydrogen, as an impurity element, weakened the interatomic bonds. Birnbaum and Sofronis [9] explained that hydrogen atmosphere shields the dislocation interactions and enhances dislocation mobility by performing stress relaxation test and theoretical calculations. The HELP theory has been further developed by elasticity theory $[9,14]$, atomistic [16-17] and thermodynamic calculations [20], in-situ TEM observations [12], and nano-mechanical tests [21-22]. Although the hydrogen enhanced dislocation mobility may

Corresponding author: Xiaofei Guo E-mail: xiaofei.guo@iehk.rwth-aachen.de, x.guo82@outlook.com 
cause material softening, the raise of yield strength and flow stress by hydrogen were also reported in austenitic stainless steels [23] and other metals [24], which states hydrogen or hydrogen clusters may act as solute hardeners for moving dislocations [23], induce slip localization [9], or facilitate dislocation nucleation at surfaces [25]. The adsorption-induced dislocation emission (AIDE) theory described both the dislocation emission due to adsorbed hydrogen and the subsequent movement of hydrogen away from the crack tip under applied stress [13]. The theory supports the frequently observed ductile fracture with the presence of hydrogen and the voids nucleation near the crack tip region. The hydrogen enhanced strain induced vacancy (HESIV) theory was first presented by Nagumo and his team $[15,26]$. The formation of strain-induced vacancies and their further agglomeration were observed with the presence of hydrogen. Since straininduced vacancies preferably occur in high dislocation density regions, voids at grain boundaries or within slip bands were observed. The resulting microvoids reduce the ductile crack growth resistance. Due to the complexity of microstructure features, loading stress status, and hydrogen concentrations, the fracture may occur by the synergistic action of a combination of the aforementioned mechanisms $[13,18,27]$. It is very important to understand the major operating mechanism and related critical influencing factors, in order to develop material with good mechanical properties as well as improved HE resistance.

TWIP steels achieve outstanding dynamic strain hardening through continuous twin nucleation and associated high dislocation density [28]. Gutierrez-Urrutia and Raabe [29] described the sequence of deformation-induced microstructural evolution in Fe-22Mn-0.6C TWIP steel, starting with developing equiaxed dislocation cells (DCs), highly dense dislocation walls (HDDWs), followed by stacking faults (SFs) formation, and eventually the nucleation and saturation of deformation twins. The stacking fault energy (SFE), which defines the energy for the dislocation dissociation, is very decisive for the nucleation of deformation twins [30]. The TWIP steels with low SFE showed high HE sensitivity due to the early twinning nucleation [4,31] or strain induced $\varepsilon / \alpha^{\prime}$ transformation [32-33]. The Al addition was reported effectively suppressing deformation twinning formation [4,31,34], reducing hydrogen mobility [35-36] and permeability due to the formation of $\mathrm{Al}_{2} \mathrm{O}_{3}$ surface layer [33]. $\mathrm{Cu}$ has the similar effects as $\mathrm{Al}$ in preventing $\mathrm{HE}$ [37]. However, the elements promoting $\varepsilon$-martensite formation, e.g., $\mathrm{Si}$, deteriorate $\mathrm{HE}$ resistance [32]. The grain refinement suppressed twin nucleation, and therefore reduces the twin-related boundaries and junctions, which enhance the HE resistance [38]. A recent research work also pointed out that the HE resistance was improved by raising the fraction of grain boundaries with rotation angle $\Sigma \leq 29$ over the random boundaries with $\Sigma>29$ [39]. These investigations demonstrated the important role of twinning nucleation and their interactions with grain boundaries as weak microstructure defects for high HE susceptibility. So far, research work on hydrogen contribution to the dislocation substructure and twin nucleation sequences at different straining stage in TWIP steels, especially based on microstructure observations, is very limited. Understanding the roles of hydrogen on the microstructure substructure and the associated fracture morphology and macroscopic mechanical properties are crucial for understanding the damaged process.

The present work characterized the macroscopic mechanical response of a Fe-22Mn-0.6C TWIP steel with different amounts of pre-charged hydrogen. The intrinsic features of the dislocation substructures, stacking fault probability, and deformation twinning nucleation with and without the presence of hydrogen have been further studied in notched tensile specimens and 0.10 pre-strained slow strain tensile specimens. The coupled electron backscattering diffraction (EBSD) and electron channelling contrast imaging (ECCI) techniques were applied for characterising microstructure at large regions with considering different grain orientations [40]. The mechanisms for the hydrogen assisted crack nucleation process were explained based on the direction observations at crack tip regions.

\section{Experimental}

\subsection{Materials}

A cold-rolled and annealed high manganese steel with the chemical composition $\mathrm{Fe}-22 \mathrm{wt} \% \mathrm{Mn}-0.6 \mathrm{wt} \% \mathrm{C}$ (abbreviated as $22 \mathrm{Mn}$ ) and thickness of $1.0 \mathrm{~mm}$ was investigated in this study. The material had fully recrystallized austenite microstructure (including annealing twins) with an average grain size of $10.2 \mu \mathrm{m}$. According to thermodynamic calculation [30] and literature [41], the investigated material has a SFE in the range of $20-28 \mathrm{~mJ} / \mathrm{m}^{2}$.

\subsection{Hydrogen charging and measurement}

To introduce diffusive hydrogen into the specimens, electrochemical pre-charging in $0.05 \mathrm{M} \mathrm{H}_{2} \mathrm{SO}_{4}+1.4 \mathrm{~g} / \mathrm{L} \mathrm{CH}_{4} \mathrm{~N}_{2} \mathrm{~S}$ aqueous solution was performed at a constant potential of $-800 \mathrm{mV}$ vs. SCE at room temperature (RT). The pre-charging was applied for two different durations, namely $24 \mathrm{~h}$ and $166 \mathrm{~h}$, respectively. Before charging, the specimen surface was mechanically grinded and finally polished with $6 \mu \mathrm{m}$ diamond paste on canvas. After charging, the specimens were ultrasonically cleaned and stored in liquid $\mathrm{N}_{2}$ for further hydrogen measurement or mechanical testing. Hydrogen contents were measured by thermal desorption spectrometry (TDS) using a quadrupole mass spectrometer at a heating rate of $6^{\circ} \mathrm{C} / \mathrm{min}$. Since hydrogen is very mobile at room temperature, to avoid unnecessary measurement deviation due to time control, the TDS measurements were carried out 
strictly after 3 or $24 \mathrm{~h}$ dwelling at room temperature. The hydrogen content after $3 \mathrm{~h}$ dwelling at room temperature is equivalent to the hydrogen amount when the tensile tests with notched tensile specimens start. The hydrogen content after $24 \mathrm{~h}$ dwelling at room temperature corresponds to the hydrogen amount in 0.10 pre-strained slow strain rate test (SSRT) specimens.

\subsection{Mechanical testing}

Tensile specimens with gauge length, width, and thickness of $25 \mathrm{~mm}, 5 \mathrm{~mm}$, and $1 \mathrm{~mm}$, respectively, were prepared by waterjet cutting. The tensile axis (TA) was parallel to the rolling direction (RD). The quasi-static mechanical properties were characterized using a ZWICK100 instrument, supplied with an extensometer, at a strain rate of $10^{-3}$ $\mathrm{s}^{-1}$. To measure the material sensitivity to $\mathrm{HE}$, as-delivered and hydrogen pre-charged specimens were characterized by SSRT using a FRITZ constant extension machine at a strain rate of $10^{-6} \mathrm{~s}^{-1}$. In addition, interrupted SSRT was carried out by terminating the test at the deformation strain of 0.10 , in order to investigate hydrogen effects on the deformed microstructural features using combined EBSD and ECCI characterization.

Notched tensile specimens with $12.5 \mathrm{~mm}$ width and a notch radius of $0.25 \mathrm{~mm}$ were prepared with the TA parallel to the RD. The specimens were pre-charged with hydrogen for $166 \mathrm{~h}$ and dwelled at RT for $3 \mathrm{~h}$ before testing. Tensile deformation with digital image correlation (DIC) measurement was then applied where the strain distribution in the vicinity of the notches was measured using a GOM-ARAMIS optical system. The direct current potential drop method was also applied in order to interrupt the tensile deformation upon primary crack nucleation, indicated by a sudden increase of electrical potential (indicating electrical resistance) [42]. The tests were performed at the strain rate of $10^{-3} \mathrm{~s}^{-1}$. More details about the tests were described in a previous work [34].

\subsection{Microstructure characterization}

The fracture surfaces of failed SSRT specimens were examined by a Zeiss Sigma Field emission scanning electron microscope (SEM) to study the fracture mode with respect to different amounts of pre-charged hydrogen. For microstructural investigation, the interrupted SSRT and notched tensile specimens were mechanically grinded to remove $\sim 100 \mu \mathrm{m}$ sub-surface, polished with diamond paste $(0.25 \mu \mathrm{m})$ and subsequently colloidal silica $(0.05 \mu \mathrm{m})$ for $3 \mathrm{~min}$. Two types of scanning electron microscopy techniques-EBSD and ECCI analysis were applied for microstructure characterization. A Zeiss Crossbeam instrument (XB 1540, Carl Zeiss SMT AG, Germany) equipped with a TSL OIM EBSD system and a solid-state four-quadrant back-scatter electron detector was used. The EBSD images revealed the local crystallographic orientation, while ECCI gave detailed information of dislo- cation substructure and the characteristics of SFs and deformation twins.

\section{Results}

\subsection{Mechanical properties}

Fig. 1 shows the true stress-strain curve and strain hardening curve of the investigated $22 \mathrm{Mn}$ steel. The material exhibits excellent mechanical properties with an ultimate tensile strength of $1087 \mathrm{MPa}$ and a total elongation of $64 \%$. The onset of serrated flow was observed at the true strain of 0.06 . This behaviour is commonly caused by the deformation twins and $\mathrm{Mn}-\mathrm{C}$ short range ordering, which act as obstacles for dislocation gliding [1]. The strain hardening curve also revealed the high strain hardening capacity compared to other structural steels, which show monotonic drop of the strain hardening rate [43]. The strain hardening rate from the investigated $22 \mathrm{Mn}$ steel remained close to $3000 \mathrm{MPa}$ for a wide strain range from the true strain of 0.07 to 0.42 . The turning point of the high strain hardening rate coincides with the onset of the serrated flow. The plateau of the high strain hardening rate is associated with high dislocation density and the subsequent microstructure refinement by deformation twinning.

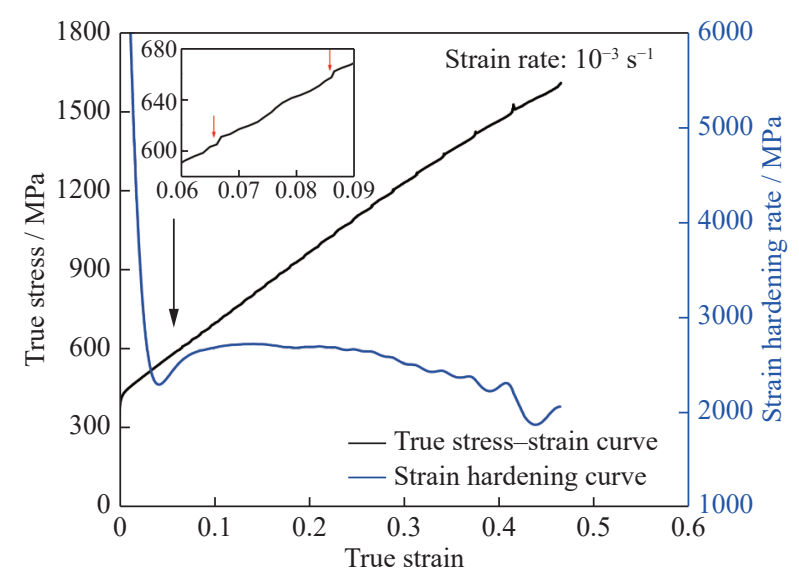

Fig. 1. Mechanical properties of the investigated 22Mn steel.

\subsection{Hydrogen diffusion and trapping}

Fig. 2 describes the hydrogen desorption curves at the constant heating rate of $6^{\circ} \mathrm{C} / \mathrm{min}$ starting at $\mathrm{RT}$ up to $800^{\circ} \mathrm{C}$. The first peak at low temperature is associated with hydrogen desorption from lattice defects where the hydrogen trapping energy is relatively low. These defects include interstitial sites, vacancies, dislocations, and twin and grain boundaries [44]. The high temperature peak is associated with the high-energy hydrogen traps, such as segregation interfaces and inclusions [45]. The hydrogen contents were presented by weight parts per million (ppm). The material contains 0 ppm diffusive and $0.5 \mathrm{ppm}$ trapped hydrogen in the as de- 
livered condition. After charging, the material displayed two prominent desorption peaks. The amounts of hydrogen under each desorption peak were fitted by the peak-fitting tool in the software Origin ${ }^{\mathrm{TM}}$, as indicated by the dashed fitting curves. The amounts of diffusive hydrogen $\left(\mathrm{H}_{\text {diff }}\right)$ were determined as 3.1 and $14.4 \mathrm{ppm}$ in the $24 \mathrm{~h}$ and $166 \mathrm{~h}$ charged and $24 \mathrm{~h}$ RT homogenized specimens, respectively. In comparison to the diffusive hydrogen, the amounts of trapped hydrogen $\left(\mathrm{H}_{\text {trap }}\right)$ were also raised to 4.9 and $9.4 \mathrm{ppm}$. The trapped hydrogen is assumed to be associated with inclusions and Mn segregations, which were frequently observed in the investigated material and discussed in a previous work [45]. The diffusive hydrogen content in a $166 \mathrm{~h}$ pre-charged and $3 \mathrm{~h}$ RT homogenized specimen reached $26.0 \mathrm{ppm}$ [34].

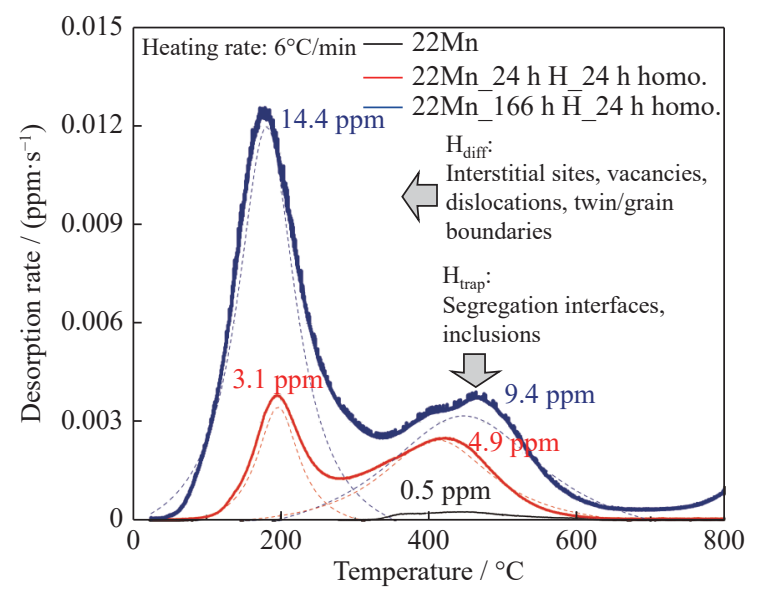

Fig. 2. Hydrogen desorption curves in as delivered and $24 \mathrm{~h}$ and $166 \mathrm{~h}$ hydrogen pre-charged and subsequently $24 \mathrm{~h}$ RT dwelled specimens (homo.- Homogenized). The amount of hydrogen under each desorption peak was fitted according to the Lorenz method with the peak-fitting tool in the software Ori$\operatorname{gin}^{\mathrm{TM}}$.

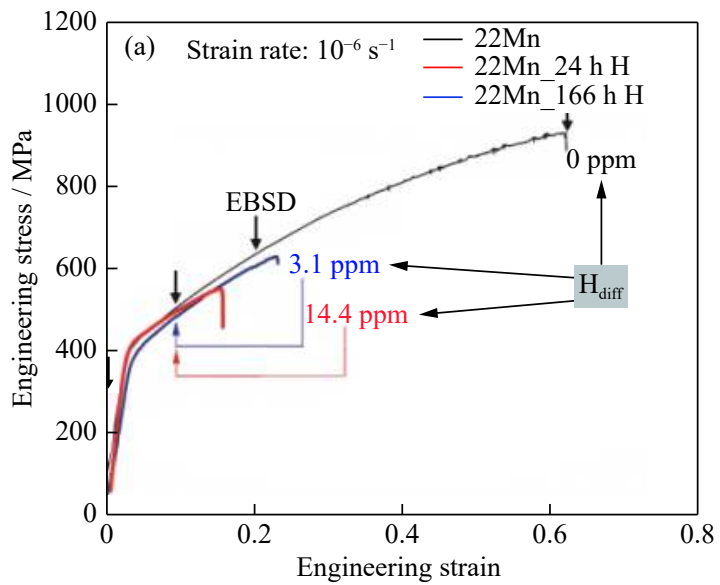

\subsection{Hydrogen effect on tensile properties and fracture mode}

Fig. 3(a) shows the SSRT engineering stress-strain curves of the 22Mn steel with different amounts of pre-charged hydrogen. Significant reduction of the engineering fracture strains was observed in hydrogen pre-charged specimens compared to the uncharged ones. The strain reduction reached $62.9 \%$ and $74.2 \%$ in the $24 \mathrm{~h}$ and $166 \mathrm{~h}$ pre-charged specimens, respectively. The amounts of diffusive hydrogen were measured with pre-charged and $24 \mathrm{~h}$ homogenized specimens, which corresponded to the amount of hydrogen when the specimens were strained close to 0.10. Compared to other high manganese TWIP steels with Al alloying evaluated by the same method [31,34,37], the investigated material showed high susceptibility to hydrogen embrittlement.

Fig. 3(b) displays EBSD image quality maps of the uncharged SSRT specimens, which were pre-strained by 0 , $0.10,0.20$ and 0.62 , respectively. The annealing twins and deformation twins are highlighted by yellow grain boundaries. In the as-delivered specimen, only annealing twins are observed. The 0.10 pre-strained specimen reveals deformation induced twins. Note that the deformation twins are not fully indexed due to the limited resolution of EBSD. The 0.20 pre-strained specimen shows more than one twin systems. In the fracture tip region with 0.62 tensile strain, high twinning density and multiple twin systems have been revealed. Except for the deformation twins, no secondary phase, such as $\varepsilon$ or $\alpha^{\prime}$ martensite was detected in the deformed microstructure.

The uncharged SSRT specimen displays a fully ductile fracture mode with a well-developed dimple structure all over the fracture surface, as displayed in Figs. 4(a)-4(a2). In comparison, the hydrogen charged specimens exhibit mixed ductile and brittle fracture modes. Fig. 4(b) reveals the fracture surface from the specimen with $3.1 \mathrm{ppm}$ diffusive hy-

(b)
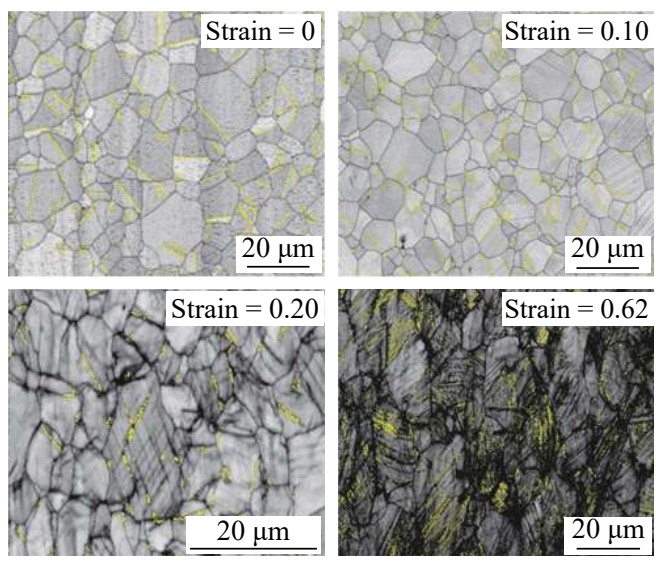

Fig. 3. (a) Engineering stress-strain curves in $22 \mathrm{Mn}$ steel with different amounts of diffusive hydrogen from slow strain test at the strain rate of $10^{-6} \mathrm{~s}^{-1}$; (b) image quality maps from EBSD characterization of microstructure for the uncharged SSRT specimens at different deformation strains. Yellow lines depict the $\Sigma 3$ twin boundaries. The used scanning step sizes are $200 \mathrm{~nm}$ for specimens with the stain of $0,0.10,0.62$ and $25 \mathrm{~nm}$ for the specimen with the strain of 0.20 . 

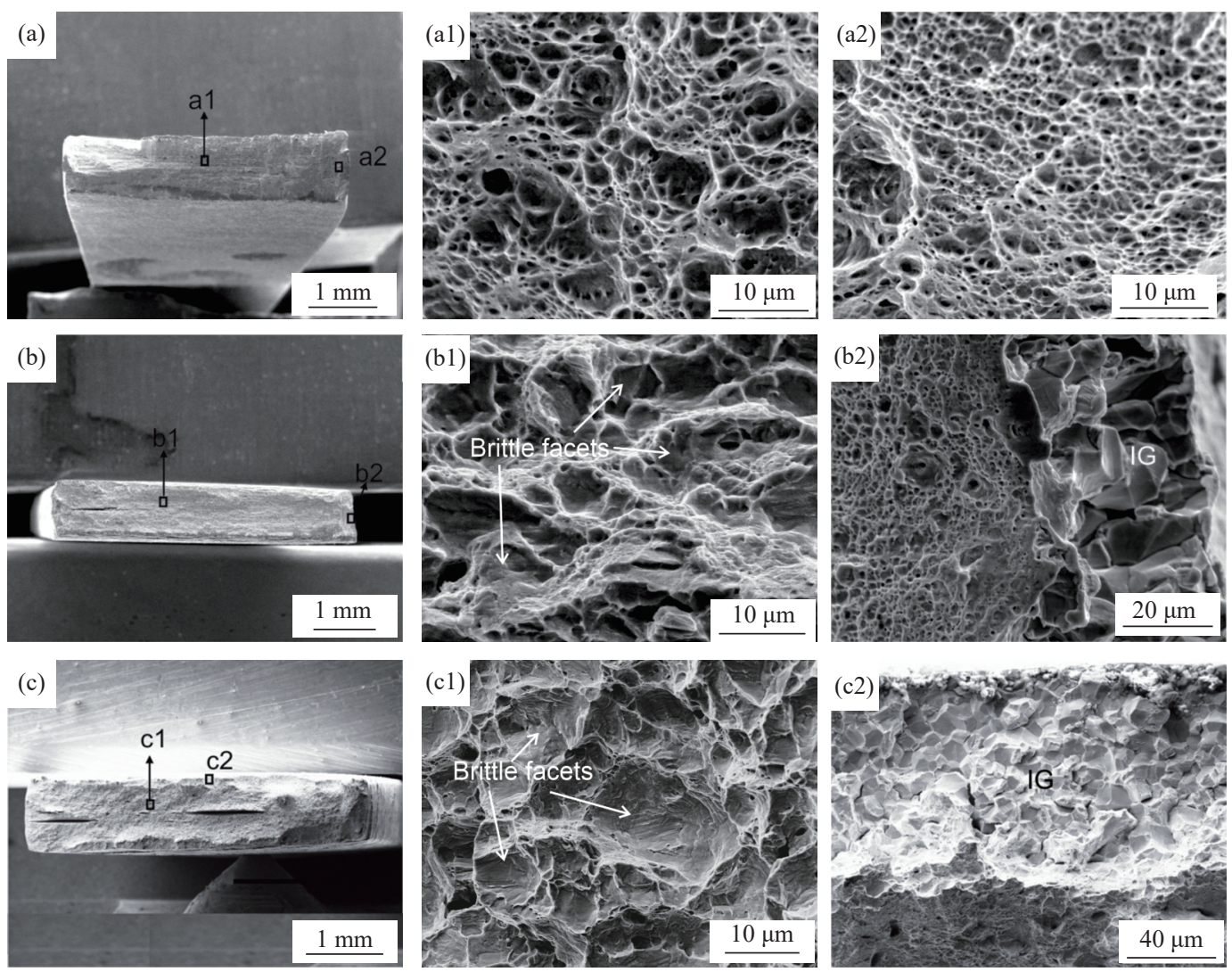

Fig. 4. Fracture surfaces of the SSRT specimens with different amounts of pre-charged hydrogen: (a-a2) 0 ppm diffusive $\mathrm{H}$, failed at the strain of 0.62 ; (b-b2) $3.1 \mathrm{ppm}$ diffusive $\mathrm{H}$, failed at the strain of 0.23 ; (c-c2) $14.4 \mathrm{ppm}$ diffusive $\mathrm{H}$, failed at the strain of 0.16 .

drogen. The central region from the fracture surface, in Fig. 4(b1), demonstrates ductile dominant fracture mode however with expanded dimple size compared to the uncharged condition. Inside the dimples, brittle facets with tearing traces can be observed, which indicate the occurrence of cleavage during void nucleation. The edge and surface regions in Fig. 4(b2) show a fully inter-granular (IG) fracture mode with the depth of $\sim 40 \mu \mathrm{m}$. Fig. 4(c) reveals the fracture surface from specimen with 14.4 ppm pre-charged hydrogen. In the central region as shown in Fig. 4(c1), although ductile traces can be observed, the trans-granular (TG) and IG fracture mode become dominant. In the surface region, in Fig. 4(c2), a fully IG with the depth of $\sim 100 \mu \mathrm{m}$ were observed. Afterwards, a transition to mixed TG and IG fracture mode with decorated ductile dimples were observed, similar as the fracture mode in the central region from the same specimens. In addition, micro-cracks were found on the fracture surface from hydrogen pre-charged specimens, which were along with the Mn segregation lines.

\subsection{Hydrogen effects on dislocation and twin substruc- ture in pre-strained SSRT specimens}

To understand the underlying mechanisms of reduced ductility, the effects of hydrogen on dislocation substructure, stacking fault probability, and twinning behaviour were fur- ther investigated by combined EBSD and ECCI characterization. Uncharged and $166 \mathrm{~h}$ hydrogen pre-charged specimens were tensile deformed at the strain rate of $10^{-6} \mathrm{~s}^{-1}$ and interrupted at the engineering strain of 0.10 . The test duration to achieve 0.10 pre-strain in the SSRT amounts to $23 \mathrm{~h}$ $40 \mathrm{~min}$. The diffusive hydrogen content in it is close to 14.4 ppm, which was measured on specimen with the same charging condition but with $24 \mathrm{~h}$ dwelling in air. Fig. 5(a) exhibits the engineering stress-strain curves from the interrupted SSRT. The hydrogen pre-charged specimen reveals lower strength than the uncharged one. The difference increases with the strain values. For both uncharged and pre-charged specimens, four EBSD maps were taken to give the grain orientation information. Fig. 5(b) shows one TA//RD-inverse pole figure (IPF) map. The grains oriented closer to the crystallographic directions $<111>/ / \mathrm{RD}$ and $<112>/$ RD have the higher Schmid factors for twinning compared to $<001>/ / R D$ orientation, which indicate high tendency for twin nucleation $[2,4]$. Therefore, the grains in these two orientations were focused. For statistical reason, 6-9 grains from each grain orientation were investigated.

Fig. 6 displays the electron channelling contrast (ECC) images of the grains oriented with $<111>/ / \mathrm{RD}$ in the 0.10 pre-strained SSRT specimens without (Figs. 6(a)-6(c)) and with ((Figs. 6(d)-6(f)) hydrogen charging. The uncharged 

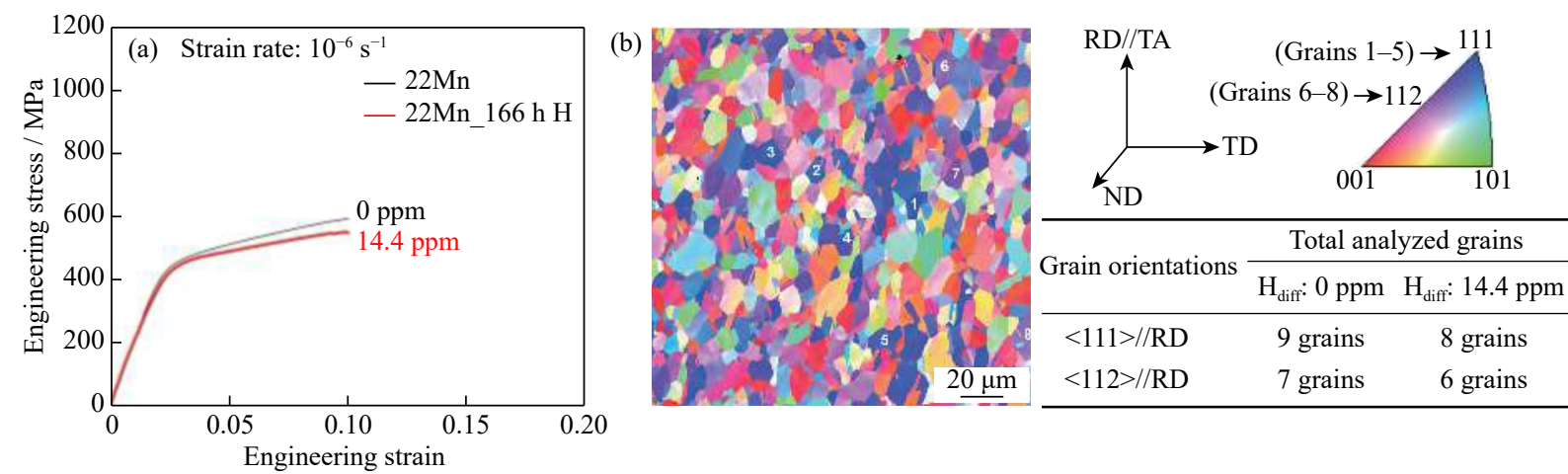

Fig. 5. (a) Engineering stress-strain curves from the as delivered and hydrogen pre-charged 22Mn steels interrupted at the strain of 0.10 during SSRT; (b) an example of a RD-IPF map with the marked grains (1-8) investigated by ECCI (ND-Normal direction; TD-Transverse direction).

specimen reveals a dislocation pattern consisting of equiaxed DCs [22-23], as shown in Figs. 6(a) and 6(b). The DCs are the typical feature in material with cross slip upon deformation [4,22]. In addition, a few deformation twins, distributed along one active twin system (the primary twin system) and not fully penetrated the grains, have been observed. In the 14.4 ppm hydrogen pre-charged specimen, in Figs. 6(d)-6(f), substantial amounts of SFs and HDDWs were frequently observed, which indicated the increased slip planarity and enhanced dislocation dissociation [4]. Compared with the average size of DCs, which are mostly with the size of $\sim 200 \mathrm{~nm}$, the distance between HDDWs is larger. The formed SFs align with the HDDWs, where abundant dislocations also impinge. The twinning densities are higher in the hydrogen charged specimen than in the uncharged one, averaged from the investigated 17 grains aligned in the $<111>/ / \mathrm{RD}$ direction. Furthermore, the secondary twin system was activated in the hydrogen pre-charged specimen as shown in Figs. 6(d) and $6(\mathrm{f})$.
Fig. 7 presents the ECC images of the grains oriented along $<112>/ /$ RD in the 0.10 pre-strained SSRT specimens without (Figs. 7(a)-7(c)) and with (Figs. 7(d)-7(f)) hydrogen charging. More planar dislocations were observed in $<112>/ /$ RD oriented grains, in Figs. 7(a) and 7(b), compared to the $<111>/ / \mathrm{RD}$ oriented grains, in Figs. 6(a) and 6(b). Higher densities of planar dislocations and SFs were also observed in the hydrogen pre-charged specimen in Fig. 7(d). In addition, hydrogen was found promoting multiple twin systems. In the uncharged and pre-strained specimen, one active twin system was usually observed, in Figs. 6(a)-6(c) and Figs. 7(a)-7(c). However, in the hydrogen pre-charged specimen at the pre-strain of 0.1 , the secondary twin system was more frequently observed, as shown in Figs. 6(d), 6(f) and Figs. 7(d)-7(f). The twin boundaries are considered as the "strongest" obstacles for dislocation movement [46]. The thickness of twin lamellae, the volume fraction of twins, and the twin spacing are important characteristics of deformation twins [47]. The thickness of twin lamellae is defined by the
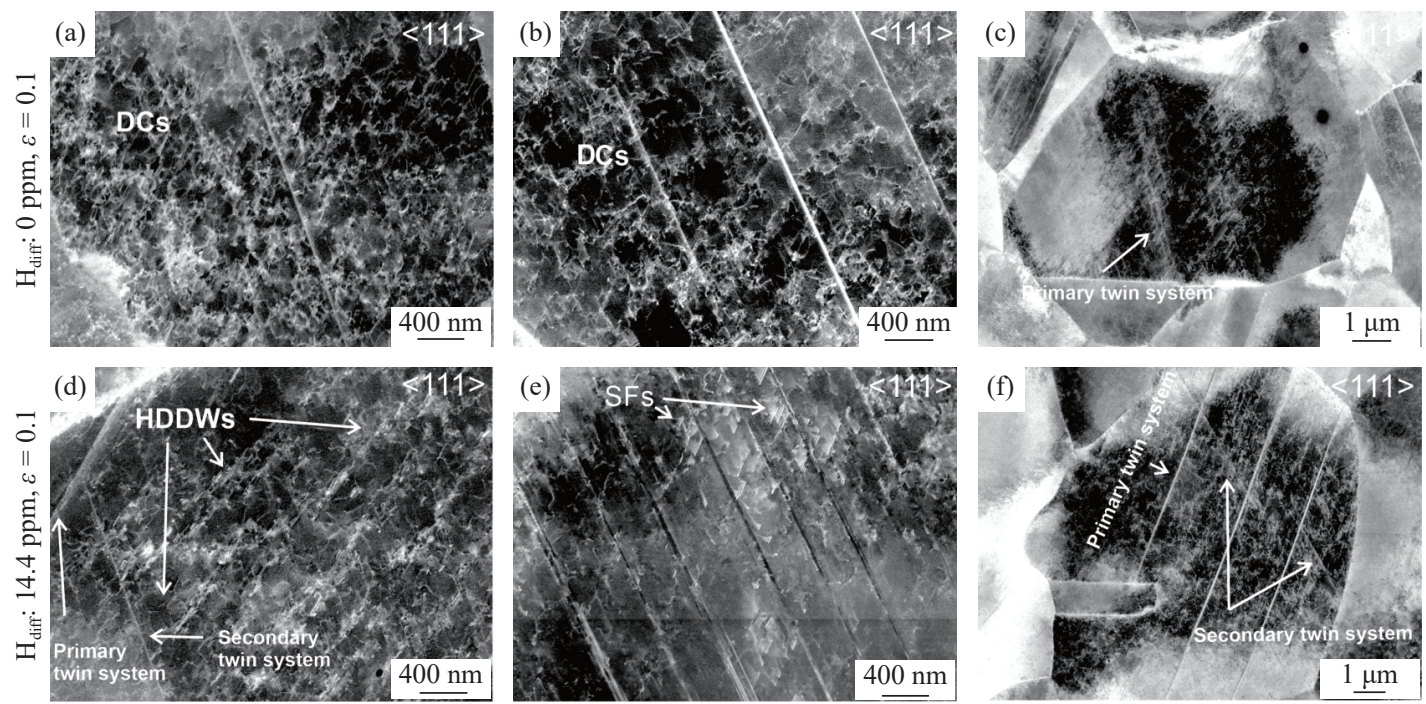

Fig. 6. ECC images of the $<111>/ /$ RD oriented grains in (a-c) uncharged and (d-f) 14.4 ppm hydrogen pre-charged SSRT specimens with the pre-strain $(\varepsilon)$ of 0.10 . 

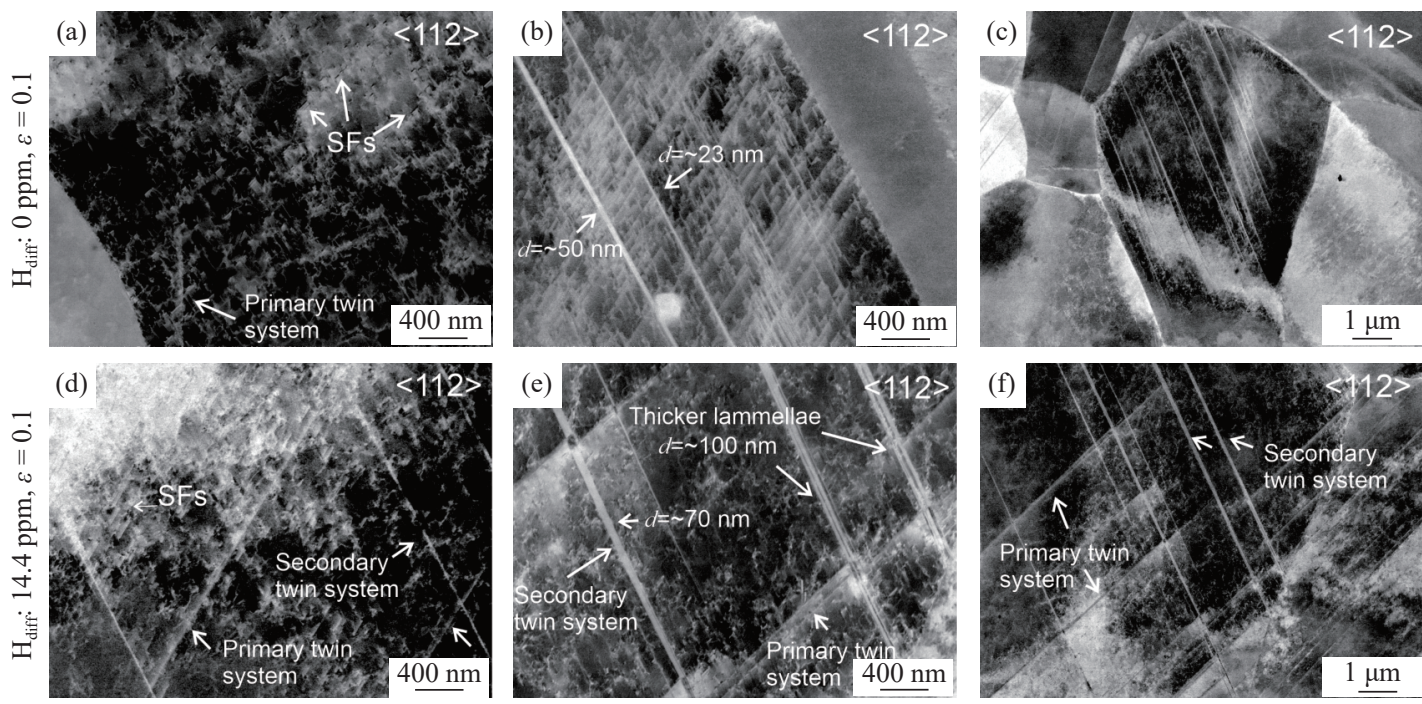

Fig. 7. ECC images of the $<\mathbf{1 1 2}>/ /$ RD oriented grains in $(a-c)$ uncharged and (d-f) $\mathbf{1 4 . 4}$ ppm hydrogen pre-charged SSRT specimens with the pre-strain of 0.10 ( $d$-Thickness of twin lamellae).

width between two boundaries of a single twin or twin stacks. As shown in Fig. 7(e), the hydrogen pre-charged specimen showed twin lamellae with the thickness of, for example, $\sim 70 \mathrm{~nm}, \sim 100 \mathrm{~nm}$ or even higher, which are wider compared to the uncharged condition, in Fig. 7(b), which are $\sim 23 \mathrm{~nm}$, $50 \mathrm{~nm}$ or lower.

\subsection{Hydrogen effects on dislocation and twin substruc- ture in notched tensile specimens}

Fig. 8 shows the ECC images and IPF maps at the notch tip region of the pre-cracked notch tensile specimens without (Figs. 8(a)-8(b)) and with (Figs. 8(c)-8(d)) hydrogen precharging. In Fig. 8(a), the uncharged specimen reveals stepwise crack propagation starting from the notch tip. The IPF map of the highlighted square in Fig. 8(a) is shown in Fig. 8(b). It reveals that the crack propagated following a TG dominated routine. In comparison, the crack in the hydrogen pre-charged specimen propagated straight along the strain gradient and remained perpendicular to the TA, as shown in Fig. 8(c). As revealed by its IPF map in Fig. 8(d), it demon-
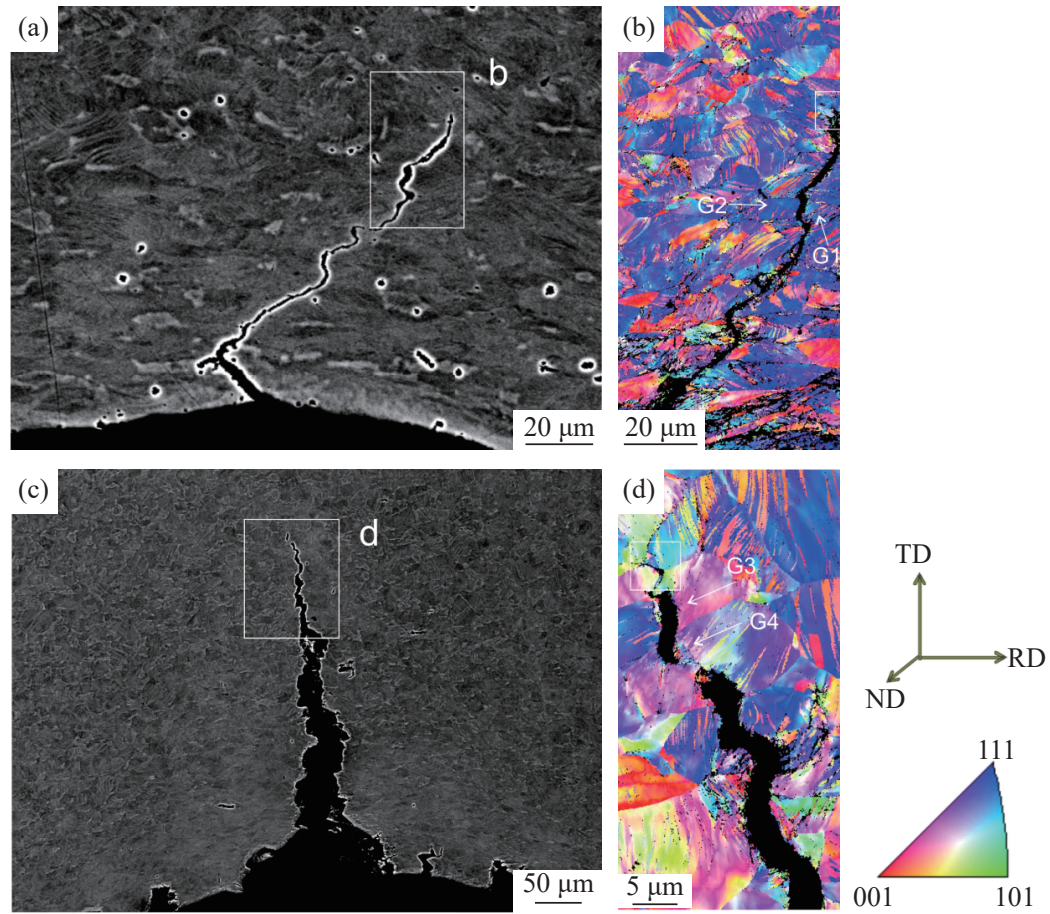

Fig. 8. ECC images and IPF maps at the notch tip region of pre-cracked notch tensile specimens (a, b) without and (c, d) with 26.0 ppm diffusive hydrogen. 
strates an IG dominated propagation path, indicating strong hydrogen degradation of the grain boundaries.

Fig. 9 reveals the ECC images of the indexed grains (G1-G4) and the crack tip regions in Figs. 8(b) and 8(d). According to DIC measurement [34], the von-Mises strains $\left(\varepsilon_{\mathrm{v}}\right)$ are at the range of $0.50-0.53$ for the uncharged specimen and $0.16-0.18$ for the pre-charged specimen at the crack tip regions, which are indicated on the right corner of each image. The main crack nucleated at the notch root initiated at the equivalent strain $\varepsilon_{\mathrm{v}}$ of 0.38 in hydrogen pre-charged specimen and 0.58 in the uncharged one. Figs. 9(a) and 9(b) display that very dense deformation twins formed in grains $\mathrm{G} 1$ and G2, which had high deformation strain in the uncharged notch tensile specimen. The second active twin system intersected with the primary twin system and caused the ladder like shearing at the intersection points. The cracks propagated perpendicular to or along the interfaces of twin lamellae, linking the sheared intersections. The crack propagated predominately trans-granularly. Figs. 9(d) and 9(e) showed the grains G3 and G4 in the hydrogen pre-charged specimen, multiple (secondary and tertiary) twin systems were observed, although they have low local deformation strain of 0.18 . Many voids were observed at the grain boundaries, as indicated by the arrows in Figs. 9(e) and 9(f). At the crack tip, in Fig. 9(f), voids and micro-cracks were observed at the grain boundaries (GBs) or triple junction of GBs. Fig. 10 presents the secondary electron imaging (SEI) image of the crack tip shown in Fig. 9(f). It clearly revealed that crack propagated through linking with the voids and micro-cracks ahead.
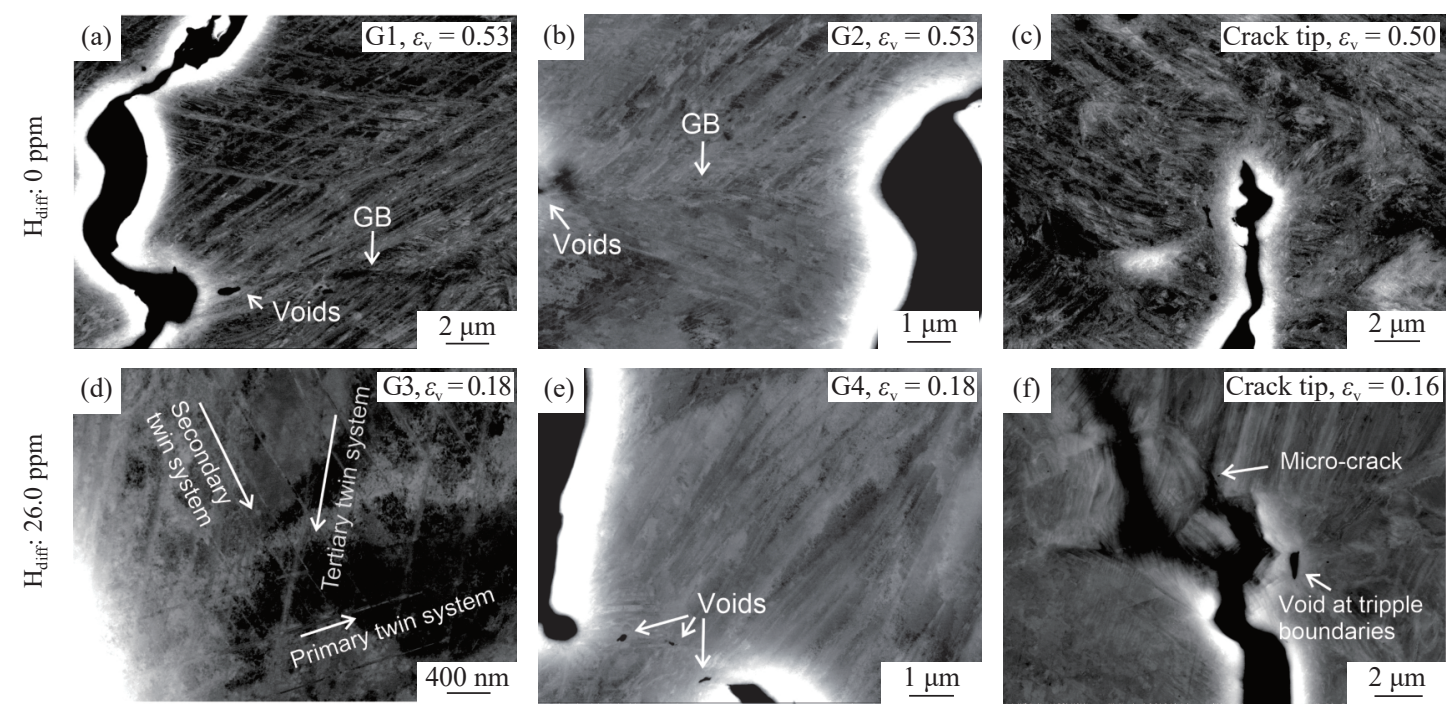

Fig. 9. ECC images of the grains at the notch tip regions in $(a-c)$ uncharged and $(d-f) 26.0$ ppm hydrogen pre-charged notch tensile specimens from 22Mn steel.

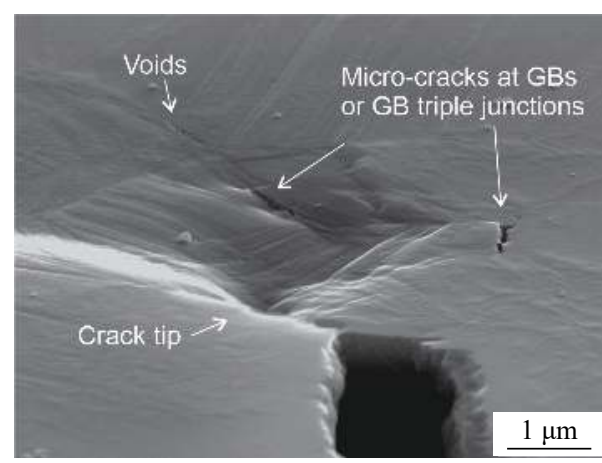

Fig. 10. SEI image of the crack tip region in hydrogen precharged notch tensile specimen.

\section{Discussion}

\subsection{The role of hydrogen on microstructure evolution}

The ECC images in Figs. 6 and 7 reveal that hydrogen promoted planar slip of dislocations and their dissociation into SFs in both $<111>/ / \mathrm{RD}$ and $<112>/ / \mathrm{RD}$ orientated grains from the 0.1 pre-strained specimens. Dislocation planarity was clearly observed in Figs. 6(d)-6(e) and Figs. 7(d)-7(e), which is different from the homogenously distributed tangled dislocations and DCs in the Figs. 6(a)-6(b). Wen et al. [48] studied hydrogen effects on cross-slip process by atomistic simulations and concluded that hydrogen was bounded to the cores of the partial dislocations and moved with the dislocations, which led to an increase of the activation energy for cross slip. Tang and El-Awady [49] confirmed that the high trapping energy of hydrogen at partial dislocation cores and edge dislocation cores by performing molecular statics simulations of nickel-hydrogen system. Hydrogen in Shockley partial core regions raised the width of SFs, meaning reducing the SFE. Hydrogen near the centre of an edge dislocation had the adverse effect. Gu and El-Awady [16] further quantified the hydrogen-dislocation interactions by discrete 
dislocation dynamics simulation. They stated that in material with large hydrogen diffusion coefficient, hydrogen would play the role of shielding effect on dislocation interactions; however, in material with low hydrogen diffusion coefficient, hydrogen tends to pin the dislocations. For the studied TWIP steel, hydrogen diffusivity in the bulk is very low [50], it is assumed that hydrogen tends to pin the dislocations. With the continuous dislocation emission from GBs with the raised deformation strain, the diffusive hydrogen will confine dislocation slip in narrow slip bands [10]. During the planar slip, hydrogen can be further transported in slip bands due to the high affinity of hydrogen to partial dislocations. Consequently, hydrogen will gradually become enriched at the dislocation pile-ups during the continuous plastic deformation at the low deformation rate of $10^{-6} \mathrm{~s}^{-1}$.

In this study, the hydrogen pre-charged specimen also revealed a high tendency to form SFs. Pontini and Hermida [51] had measured 37\% reduction in SFE in an AISI 304 austenitic stainless steel with the presence of $274 \mathrm{ppm}$ hydrogen by X-ray diffraction, and Hermida and Roviglione [52] explained that this was due to the formation of $\mathrm{H}-\mathrm{H}$ pairs. Quantum mechanics calculations in different studies further confirmed the energetic stability of $\mathrm{H}$ atoms as well as $\mathrm{H}-\mathrm{H}$ pairs at the SFs [53-54]. Although Tang and El-Awady [49] found that hydrogen effect on SFE was dependent on the crystallographic location of hydrogen, the current work demonstrated that SFs were promoted in hydrogen charged specimens. High amounts of SFs were found along the slip bands, which have both high dislocation density and enriched hydrogen. The local hydrogen concentration will be much higher than the average value of $14.4 \mathrm{ppm}$, not only due to hydrogen affinity to dislocation, but also due to the charging induced hydrogen enrichment in the sub-surface region.

It is well established that mechanical twinning is the result of the collaborative glide of intrinsic a/ $6<112>$ Shockley partial dislocations on successive parallel $\{111\}$ planes. The crystallographic structure between the faulted boundaries has a $\Sigma 3$ orientation compared to the matrix [28]. In the investigated material, the grains oriented close to $<111>/ / R D$, and $<112>/ / \mathrm{RD}$ are favourable orientations for twin nucleation. With pre-charged hydrogen, narrow twin spacing and more active twin systems had been observed in the investigated $22 \mathrm{Mn}$ steel. It is assumed that the resolved shear stress for twin nucleation declines due to the reduced SFE [55], which is also in consistence with a recent research about hydrogen effect on twin spacing [56]. In addition, with charged hydrogen, the secondary twin system became active in the 0.1 prestrained SSRT specimen, and tertiary twin system was observed in the notch tip region with high triaxiality.

Another observed feature is that the thickening of twin lamellae was found in the hydrogen charged specimen, as observed in Fig. 7(e) compared to Fig. 7(b). The thickness $(e)$ of deformation twin lamellae is proportional to the applied shear stress $\left(\tau_{\text {applied }}\right)[47]$.

$$
S=\frac{e}{D}=\frac{2 d_{111}}{\mu b}\left(\tau_{\text {applied }}-\tau_{\text {loop }}\right)
$$

where $S$ is the shape factor of a twin, $e$ represents twin thickness, $D$ represents the twin radius, $d_{111}$ represents the distance between the (111) planes, $b$ represents the Burgers' vector of Shockley partials, and $\tau_{\text {loop }}$ represents the critical stress to expand a dislocation loop. With the presence of hydrogen, the critical stress to expand a dislocation loop is reduced [57]. Although the $\tau_{\text {applied }}$ seems declined in the hydrogen charged specimen as shown in Fig. 5, it does not consider the hydrogen induced surface cracks during the straining process. A recent research on revealing the surface cracks evolution during in-situ tensile testing under SEM showed that the $\tau_{\text {applied }}$ is usually underestimated [58]. Because the cross section to calculate $\tau_{\text {applied }}$ should exclude the surface cracks, which has the similar size as the measured brittle area on the fracture head. When considering the width of the brittle area is $\sim 100 \mu \mathrm{m}$ (estimated from Fig. 4(c2)) for the $166 \mathrm{~h}$ charged specimen, which failed at the strain of 0.16 . For Fig. 5(a), by assuming the width of brittle area has linear dependence on the tensile strain, the calibrated $\tau_{\text {applied }}$ at the strain of 0.1 would be raised from 545 to $620 \mathrm{MPa}$, which is above the stress value from uncharged specimen (590 MPa). According to Eq. (1), the twin thickening would be promoted by hydrogen, which is in consistence with the observations in Fig. 7. Müllner [59] described in a twin intersection model that the twin intersection stress decreases with increasing twin thickness, indicating less hardening effect than thinner twins. In the other aspect, the thicker twins usually containing higher density of dislocations [54], which are effective hydrogen carriers [60]. Therefore, the damage initiation at twin-twin intersections will be resulted from the local stress condition coupled with local hydrogen concentration. However, when the thick twin bundles impede with the "harder" obstacles, such as grain boundaries, higher tendency for crack formation will be promoted due to the larger exerted stress.

\subsection{Hydrogen embrittlement mechanisms in the invest- igated material}

According to the ECCI observations, hydrogen effects on promoting dislocation planarity, SFs formation, multiple twin systems, and twin thickening gave information about its influences on microstructure. The associated substructure features led to material strengthening at the early stage $[2,29]$, and slip localization occurs consequently $[3,13]$. The increasing in slip planarity and the slip activation on additional planes are consistent with the proposed HELP mechanism $[9,12,14]$. A recent investigation on the nano-mechanical response to hydrogen by in-situ nano-indentation on coarse- 
grained material with the same chemistry also supported the operating of HELP mechanism inside single grains [60]. Both dislocation formation energy and the size of plastic zone beneath the indents were reduced by hydrogen. The nano-hardness inside of single grains was raised, meaning the material hardening inside grains. Because no matter hydrogen facilitates dislocation movement [9] or pins dislocation movement [16], the promoted dislocation planarity leads to the pile-up of dislocations [23]. Either higher applied stress is needed to concur the back stress of dislocation pile-ups or the pile-ups are released by local decohesion. As a result, the macroscopic decohesion at the grain boundaries is associated with the activation of HELP mechanism inside the grains. More specifically to say, the intra-granularly HELP assisted grain boundary decohesion.

As observed in the fracture surfaces from SSRT specimens in Fig. 4, there is a clear embrittlement zone at the subsurface in the hydrogen charged specimens. A sketch of the fracture modes across specimen cross section is described in Fig. 11. The fully IG fracture mode at the sub-surface demonstrated the HEDE dominated mechanism in this region (dark grey). This near surface region contained higher amount of hydrogen, as indicated by the hydrogen distribution profile (red line). The transition zone from fully IG to mixed facture modes is exactly where the ECCI observation were performed. In this region, hydrogen promoted dislocation planarity, SFs, multiple twin systems, and their interaction with grain boundaries coexisted. The mixed fracture mode revealed intergranular facets, quasi-cleavage as well as deformation dimples. The interplay of HELP, HESIV and HEDE mechanisms should take place in this region. Toward the bulk centre, the growing surface cracks would lead to a stress filed ahead their crack tips (blue line). The operating mechanisms are similar as the triaxial stress field ahead of notched specimens [61], leading to significant twin formation and the associated micro-voids nucleation. Without charged hydrogen, the cracks could propagate in the ductile dominated mode, depending on the instability of the microvoids upon straining. With charged hydrogen, on the one side, the SFs and twinning are promoted which lead to abundant voids nucleation at low strains; on the other side, hydrogen atoms are more easily transported by dislocations

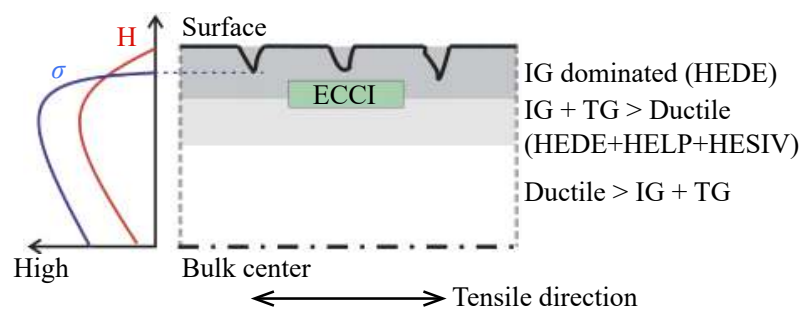

Fig. 11. Fracture modes and operating HE mechanisms from specimen surface to center. Red curve describes $\mathbf{H}$ distribution profile; blue curve describes stress $(\sigma)$ distribution profile. gliding to these voids, since the low strain rate facilitates the transportation of hydrogen by moving dislocations [62]. The incoherent GBs would be the preferential hydrogen trapping sites to accommodate larger amount of hydrogen atoms. As a result, the accumulated hydrogen at GBs would cause decohesion and lead to micro-cracks, especially at twin-GB intersections or GB triple junctions, as revealed in the crack tip region in Fig. 10.

\section{Conclusions}

The present work revealed hydrogen effects on the mechanical properties, fracture modes, and microstructural features in a high manganese Fe-22Mn-0.6C TWIP steel. The coupled EBSD and ECCI analysis gave detailed information about the dislocation substructure, stacking fault probability, and deformation twinning behaviour at different strain levels, as affected by diffusive hydrogen. The main results are summarized as follows.

(1) The investigated steel showed high HE susceptibility with the reduction of $62.9 \%$ and $74.2 \%$ in engineering strain with $3.1 \mathrm{ppm}$ and $14.4 \mathrm{ppm}$ diffusive hydrogen. The fracture surfaces revealed a transition from ductile to brittle dominated fracture mode with the rising hydrogen contents.

(2) Hydrogen promoted dislocation planarity, earlier nucleation of SFs and deformation twinning as well as multiple twin systems in the grains oriented close to $<111>/ / \mathrm{RD}$ and $<112>/ /$ RD as revealed by ECCI at the subsurface. Subsequently, the promoted microstructural defects hardened the material intra-granularly. However, they led to strain localization and micro-voids at grain boundaries or intersections of the multiple twin systems. Diffusive hydrogen accumulated easier at these strain localized sites through dislocation transportation or grain boundary diffusion. Eventually, HEDE mechanism was found to be the prevailing failure mechanism in the hydrogen enriched subsurface region. Multiple HE mechanisms interplay toward the specimen bulk.

\section{Acknowledgements}

This work was supported by German Research Foundation (DFG) in the framework of the Collaborative Research Center SFB 761 "Steel ab initio". The authors also acknowledge Dr. Sergiy Merzlikin and Ms. Monika Nellessen from Max-Planck Institute für Eisenforschung for their help in carrying out the TDS and ECCI measurements.

Open Access funding enabled and organized by Projekt DEAL.

Open Access This article is licensed under a Creative Commons Attribution 4.0 International License, which permits use, sharing, adaptation, distribution and reproduction in any medium or format, as long as you give appropriate credit to the original author(s) and 
the source, provide a link to the Creative Commons licence, and indicate if changes were made. The images or other third party material in this article are included in the article's Creative Commons licence, unless indicated otherwise in a credit line to the material. If material is not included in the article's Creative Commons licence and your intended use is not permitted by statutory regulation or exceeds the permitted use, you will need to obtain permission directly from the copyright holder. To view a copy of this licence, visit http://creativecommons.org/licenses/by/4.0/.

\section{References}

[1] B.C. De Cooman, K.-G. Chin, and J. Kim, High Mn TWIP steels for automotive applications, [in] M. Chiaberge, ed., New Trends and Developments in Automotive System Engineering, IntechOpen, Rijeka, 2011.

[2] H. Idrissi, K. Renard, L. Ryelandt, D. Schryvers, and P.J. Jacques, On the mechanism of twin formation in $\mathrm{Fe}-\mathrm{Mn}-\mathrm{C}$ TWIP steels, Acta Mater., 58(2010), No. 7, p. 2464.

[3] C.L. Yang, Z.J. Zhang, P. Zhang, and Z.F. Zhang, The premature necking of twinning-induced plasticity steels, Acta Mater., 136(2017), p. 1

[4] J.S. Kim, Y.H. Lee, D.L. Lee, K.-T. Park, and C.S. Lee, Microstructural influences on hydrogen delayed fracture of high strength steels, Mater. Sci. Eng. A, 505(2009), No. 1-2, p. 105.

[5] M. Koyama, E. Akiyama, K. Tsuzaki, and D. Raabe, Hydrogenassisted failure in a twinning-induced plasticity steel studied under in situ hydrogen charging by electron channeling contrast imaging, Acta Mater., 61(2013), No. 12, p. 4607.

[6] M. Koyama, E. Akiyama, Y.-K. Lee, D. Raabe, and K. Tsuzaki, Overview of hydrogen embrittlement in high-Mn steels, Int. J. Hydrogen Energy, 42(2017), No. 17, p. 12706.

[7] C.D. Beachem, A new model for hydrogen-assisted cracking (hydrogen "embrittlement"), Metall. Mater. Trans. B, 3(1972), No. 2, p. 441.

[8] S.P. Lynch, Environmentally assisted cracking: Overview of evidence for an adsorption-induced localised-slip process, Acta Metall., 36(1988), No. 10, p. 2639.

[9] H.K. Birnbaum and P. Sofronis, Hydrogen-enhanced localized plasticity-A mechanism for hydrogen-related fracture, Mater. Sci. Eng. A, 176(1994), No. 1-2, p. 191.

[10] D.P. Abraham and C.J. Altstetter, Hydrogen-enhanced localization of plasticity in an austenitic stainless steel, Metall. Mater. Trans. A, 26(1995), No. 11, p. 2859

[11] C.J. McMahon, Hydrogen-induced intergranular fracture of steels, Eng. Fract. Mech., 68(2001), No. 6, p. 773.

[12] I.M. Robertson, The effect of hydrogen on dislocation dynamics, Eng. Fract. Mech., 68(2001), No. 6, p. 671.

[13] S. Lynch, Hydrogen embrittlement phenomena and mechanisms, Corros. Rev., 30(2012), No. 3-4, p. 105.

[14] K.A. Nibur, D.F. Bahr, and B.P. Somerday, Hydrogen effects on dislocation activity in austenitic stainless steel, Acta Mater. 54(2006), No. 10, p. 2677.

[15] M. Nagumo and K. Takai, The predominant role of strain-induced vacancies in hydrogen embrittlement of steels: Overview, Acta Mater., 165(2019), p. 722.

[16] Y.J. Gu and J.A. El-Awady, Quantifying the effect of hydrogen on dislocation dynamics: A three-dimensional discrete dislocation dynamics framework, J. Mech. Phys. Solids, 112(2018), p. 491
[17] J.P. Chateau, D. Delafosse, and T. Magnin, Numerical simulations of hydrogen-dislocation interactions in fcc stainless steels. Part I: Hydrogen-dislocation interactions in bulk crystals, Acta Mater., 50(2002), No. 6, p. 1507.

[18] A. Nagao, M. Dadfarnia, B.P. Somerday, P. Sofronis, and R.O. Ritchie, Hydrogen-enhanced-plasticity mediated decohesion for hydrogen-induced intergranular and "quasi-cleavage" fracture of lath martensitic steels, J. Mech. Phys. Solids, 112(2018), p. 403.

[19] P. Novak, R. Yuan, B.P. Somerday, P. Sofronis, and R.O. Ritchie, A statistical, physical-based, micro-mechanical model of hydrogen-induced intergranular fracture in steel, J. Mech. Phys. Solids, 58(2010), No. 2, p. 206.

[20] R. Kirchheim, Reducing grain boundary, dislocation line and vacancy formation energies by solute segregation. I. Theoretical background, Acta Mater., 55(2007), No. 15, p. 5129.

[21] A. Barnoush, M. Asgari, and R. Johnsen, Resolving the hydrogen effect on dislocation nucleation and mobility by electrochemical nanoindentation, Scripta Mater., 66(2012), No. 6, p. 414.

[22] A. Barnoush and H. Vehoff, Recent developments in the study of hydrogen embrittlement: Hydrogen effect on dislocation nucleation, Acta Mater., 58(2010), No. 16, p. 5274.

[23] D.P. Abraham and C.J. Altstetter, The effect of hydrogen on the yield and flow stress of an austenitic stainless steel, Metall. Mater. Trans. A, 26(1995), No. 11, p. 2849.

[24] C. Verpoort, D.J. Duquette, N.S. Stoloff, and A. Neu, The influence of plastic deformation on the hydrogen embrittlement of nickel, Mater. Sci. Eng., 64(1984), No. 1, p. 135.

[25] J.A. Clum, The role of hydrogen in dislocation generation in iron alloys, Scripta Metall., 9(1975), No. 1, p. 51.

[26] M. Hatano, M. Fujinami, K. Arai, H. Fujii, and M. Nagumo, Hydrogen embrittlement of austenitic stainless steels revealed by deformation microstructures and strain-induced creation of vacancies, Acta Mater., 67(2014), p. 342.

[27] Z.D. Harris, S.K. Lawrence, D.L. Medlin, G. Guetard, J.T. Burns, and B.P. Somerday, Elucidating the contribution of mobile hydrogen-deformation interactions to hydrogen-induced intergranular cracking in polycrystalline nickel, Acta Mater., 158(2018), p. 180.

[28] O. Bouaziz, S. Allain, C.P. Scott, P. Cugy, and D. Barbier, High manganese austenitic twinning induced plasticity steels: A review of the microstructure properties relationships, Curr. Opin. Solid State Mater. Sci., 15(2011), No. 4, p. 141.

[29] I. Gutierrez-Urrutia and D. Raabe, Dislocation and twin substructure evolution during strain hardening of an Fe-22wt.\% Mn-0.6wt.\% C TWIP steel observed by electron channeling contrast imaging, Acta Mater., 59(2011), No. 16, p. 6449.

[30] A. Saeed-Akbari, J. Imlau, U. Prahl, and W. Bleck, Derivation and variation in composition-dependent stacking fault energy maps based on subregular solution model in high-manganese steels, Metall. Mater. Trans. A, 40(2009), No. 13, p. 3076.

[31] K.G. Chin, C.Y. Kang, S.Y. Shin, S. Hong, S. Lee, H.S. Kim, K.H. Kim, and N.J. Kim, Effects of Al addition on deformation and fracture mechanisms in two high manganese TWIP steels, Mater. Sci. Eng. A, 528(2011), No. 6, p. 2922.

[32] S.M. Lee, I.J. Park, J.G. Jung, and Y.K. Lee, The effect of Si on hydrogen embrittlement of $\mathrm{Fe}-18 \mathrm{Mn}-0.6 \mathrm{C}-x \mathrm{Si}$ twinning-induced plasticity steels, Acta Mater., 103(2016), p. 264.

[33] I.J. Park, K.H. Jeong, J.G. Jung, C.S. Lee, and Y.K. Lee, The mechanism of enhanced resistance to the hydrogen delayed fracture in Al-added $\mathrm{Fe}-18 \mathrm{Mn}-0.6 \mathrm{C}$ twinning-induced plasticity steels, Int. J. Hydrogen Energy, 37(2012), No. 12, p. 9925. 
[34] X.F. Guo, S. Zaefferer, F. Archie, and W. Bleck, Dislocation and twinning behaviors in high manganese steels in respect to hydrogen and aluminium alloying, Procedia Struct. Integrity, 13(2018), p. 1453.

[35] Y.S. Chun, K.T. Park, and C.S. Lee, Delayed static failure of twinning-induced plasticity steels, Scripta Mater., 66(2012), No. 12, p. 960.

[36] M. Koyama, E. Akiyama, and K. Tsuzaki, Hydrogen embrittlement in Al-added twinning-induced plasticity steels evaluated by tensile tests during hydrogen charging, ISIJ Int., 52(2012), No. 12, p. 2283.

[37] T. Dieudonné, L. Marchetti, M. Wery, J. Chêne, C. Allely, P. Cugy, and C.P. Scott, Role of copper and aluminum additions on the hydrogen embrittlement susceptibility of austenitic Fe-Mn-C TWIP steels, Corros. Sci., 82(2014), p. 218.

[38] N. Zan, H. Ding, X.F. Guo, Z.Y. Tang, and W. Bleck, Effects of grain size on hydrogen embrittlement in a $\mathrm{Fe}-22 \mathrm{Mn}-0.6 \mathrm{C}$ TWIP steel, Int. J. Hydrogen Energy, 40(2015), No. 33, p. 10687.

[39] Y.J. Kwon, S.P. Jung, B.J. Lee, and C.S. Lee, Grain boundary engineering approach to improve hydrogen embrittlement resistance in $\mathrm{Fe}-\mathrm{Mn}-\mathrm{C}$ TWIP steel, Int. J. Hydrogen Energy, 43(2018), No. 21, p. 10129.

[40] S. Zaefferer and N.N. Elhami, Theory and application of electron channelling contrast imaging under controlled diffraction conditions, Acta Mater., 75(2014), p. 20.

[41] A. Dumay, J.-P. Chateau, S. Allain, S. Migot, and O. Bouaziz, Influence of addition elements on the stacking-fault energy and mechanical properties of an austenitic Fe-Mn-C steel, Mater. Sci. Eng. A, 483-484(2008), p. 184.

[42] J. Lian, M. Sharaf, F. Archie, and S. Münstermann, A hybrid approach for modelling of plasticity and failure behaviour of advanced high-strength steel sheets, Int. J. Damage Mech., 22(2013), No. 2, p. 188.

[43] F. Ozturk, A. Polat, S. Toros, and R.C. Picu, Strain hardening and strain rate sensitivity behaviors of advanced high strength steels, J. Iron Steel Res. Int., 20(2013), No. 6, p. 68.

[44] D.P. Escobar, T. Depover, L. Duprez, K. Verbeken, and M. Verhaege, Combined thermal desorption spectroscopy, differential scanning calorimetry, scanning electron microscopy and Xray diffraction study of hydrogen trapping in cold deformed TRIP steel, Acta Mater., 60(2012), No. 6-7, p. 2593.

[45] X.F. Guo, Influences of Microstructure, Alloying Elements and Forming Parameters on Delayed Fracture in TRIP/TWIP-Aided Austenitic Steels [Dissertation], RWTH Aachen University, Aachen, 2012, p. 88.

[46] D. Kuhlmann-Wilsdorf, Theory of plastic deformation - Properties of low energy dislocation structures, Mater. Sci. Eng. A, 113(1989), p. 1.

[47] S. Allain, J.-P. Chateau, D. Dahmoun, and O. Bouaziz, Modelling of mechanical twinning in a high manganese content aus- tenitic steel, Mater. Sci. Eng. A, 387-389(2004), p. 272.

[48] M. Wen, S. Fukuyama, and K. Yokogawa, Hydrogen-affected cross-slip process in fcc nickel, Phys. Rev. B, 69(2004), No. 17, art. No. 174108.

[49] Y.Z. Tang and J.A. El-Awady, Atomistic simulations of the interactions of hydrogen with dislocations in fcc metals, Phys. Rev. B, 86(2012), No. 17, art. No. 174102.

[50] D.K. Han, S.K. Lee, S.J. Noh, S.-K. Kim, and D.-W. Suh, Effect of aluminium on hydrogen permeation of high-manganese twinning-induced plasticity steel, Scripta Mater., 99(2015), p. 45.

[51] A.E. Pontini and J.D. Hermida, X-Ray diffraction measurement of the stacking fault energy reduction induced by hydrogen in an AISI 304 steel, Scripta Mater., 37(1997), No. 11, p. 1831.

[52] J.D. Hermida and A. Roviglione, Stacking fault energy decrease in austenitic stainless steels induced by hydrogen pairs formation, Scripta Mater., 39(1998), No. 8, p. 1145.

[53] J. von Appen, R. Dronskowski, A. Chakrabarty, T. Hickel, R. Spatschek, and J. Neugebauer, Impact of Mn on the solution enthalpy of hydrogen in austenitic Fe-Mn alloys: A first-principles study, J. Comput. Chem., 35(2014), No. 31, p. 2239.

[54] J.B. Cohen and J. Weertman, A dislocation model for twinning in f.c.c. metals, Acta Metall., 11(1963), No. 8, p. 996.

[55] D. Steinmetz, A Constitutive Model of Twin Nucleation and Deformation Twinning in High-Manganese Austenitic TWIP Steels [Dissertation], RWTH Aachen University, Aachen, 2013.

[56] B. Bal, M. Koyama, G. Gerstein, H.J. Maier, and K. Tsuzaki, Effect of strain rate on hydrogen embrittlement susceptibility of twinning-induced plasticity steel pre-charged with high-pressure hydrogen gas, Int. J. Hydrogen Energy, 41(2016), No. 34, p. 15362

[57] S. Evers and M. Rohwerder, The hydrogen electrode in the "dry": A Kelvin probe approach to measuring hydrogen in metals, Electrochem. Commun., 24(2012), p. 85.

[58] D. Wang, X. Lu, D. Wan, X.F. Guo, R. Johnsen, Effect of hydrogen on the embrittlement susceptibility of Fe-22Mn-0.6C TWIP steel revealed by in-situ tensile tests, Mater. Sci. Eng. A, 802(2021), art. No. 140638.

[59] P. Müllner, Disclination models for deformation twinning, Solid State Phenom., 87(2002), p. 227.

[60] D. Wang, X. Lu, Y. Deng, X.F. Guo, and A. Barnoush, Effect of hydrogen on nanomechanical properties in $\mathrm{Fe}-22 \mathrm{Mn}-0.6 \mathrm{C}$ TWIP steel revealed by in-situ electrochemical nanoindentation, Acta Mater., 166(2019), p. 618.

[61] M. Faccoli, G. Cornacchia, M. Gelfi, A. Panvini, and R. Roberti, Notch ductility of steels for automotive components, Eng. Fract. Mech., 127(2014), p. 181.

[62] J. Rehrl, K. Mraczek, A. Pichler, and E. Werner, Mechanical properties and fracture behavior of hydrogen charged AHSS/UHSS grades at high- and low strain rate tests, Mater. Sci. Eng. A, 590(2014), p. 360. 